\title{
Phosphinate MOF formed from tetratopic ligands as proton conductive materials
}

\author{
Matouš Kloda, ${ }^{a *}$ Tomáš Plecháček, ${ }^{b}$ Soňa Ondrušová, ${ }^{a}$ Petr Brázda,${ }^{c}$ Petr Chalupský, ${ }^{a}$ Jan \\ Rohlíček, ${ }^{c}$ Jan Demel, ${ }^{a}$ Jan Hynek, ${ }^{a *}$

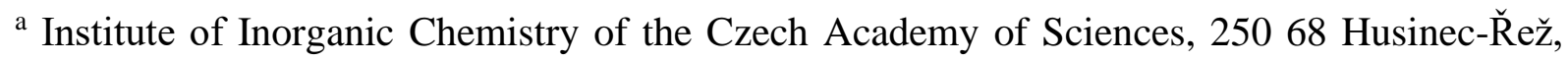 \\ Czech Republic; E-mails: hynek@iic.cas.cz; kloda@iic.cas.cz \\ ${ }^{\mathrm{b}}$ Faculty of Chemical Technology, University of Pardubice, 53210 Pardubice, Czech \\ Republic \\ ${ }^{\mathrm{c}}$ Institute of Physics of the Czech Academy of Sciences, 18221 Praha, Czech Republic
}

\begin{abstract}
Metal organic frameworks (MOFs) are attracting attention as potential proton conductors. There are two main advantages of MOFs in this application: the possibility of rational design and tuning of the properties, and clear conduction pathways given by their crystalline structure. We hereby present two new MOF structures, ICR-10 and ICR-11, based on tetratopic phosphinate ligands. The structures of both MOFs were determined by $3 \mathrm{D}$ electron diffraction. They both crystallize in the $P-3$ space group and contain arrays of parallel linear pores lined with hydrophilic non-coordinated phosphinate groups. This, together with the adsorbed water molecules, facilitates proton transfer via the Grotthuss mechanism, leading to the proton conductivity up to $4.26 \cdot 10^{-4} \mathrm{~S} \mathrm{~cm}^{-1}$ for ICR-11.
\end{abstract}

\section{Introduction}

In recent years, solid state proton conductors have been widely studied for various applications including sensors, batteries, fuel cells and other areas [1]. Particularly, fuel cells are important due to the worldwide growing energy demand and ongoing search for alternative energy sources. Solid proton conductors in this case serve as a component of membranes that separate the two half reactions but enable the transfer of protons to complete the overall reaction. Up to date, commonly used membranes are usually based on Nafion (sulfonated fluoropolymer), however, such materials suffer from several problems, including manufacturing price, limited permeability for certain fuels and poor crystallinity making in-depth analysis of the proton transfer mechanism impossible [2]. For those reasons, ongoing research is looking for more suitable proton conducting materials.

A class of materials which attracts considerable attention are metal-organic frameworks (MOFs). Their main advantages as proton conductors are their porous nature, tunability of the structure and the possibility of rational design taking advantage of using different molecular components [3]. Furthermore, the crystalline structure of MOFs enables the elucidation of proton transfer mechanism at the molecular level. The proton conduction in MOFs can be facilitated by coordinated molecules such as water [4], non-coordinated acidic groups in the network [5] or guest molecules in the channels [6]. In particular, MOFs containing channels lined with hydrophilic groups are of interest since they can form hydrogen-bonded network with water molecules, which effectively facilitates the transport of protons [5,7].

Only a couple of years ago first MOFs composed of ligands bearing phosphinate coordination groups were synthetized [8]. These phosphinate MOFs are of particular interest due to their 
stability and the possibility of isoreticular design [9]. While the closely related phosphonate coordination polymers and MOFs have been extensively studied in terms of proton conductivity $[10,11,12]$, the development of novel phosphonate MOFs is laborious and the structures are hard to predict $[13,14]$.

Up to now, only a few examples of proton conductive phosphinates have been reported. Bis(trifluoromethyl)phosphinic acid was used as a model compound for phosphinate analogue of a Nafion-type polymer. The material revealed enhanced properties, especially under low humidity conditions [15]. Crystalline proton conductive phosphinates are represented by the MOF based on triphosphaazatriangulene ligand that exhibits a phase transition into a nonporous columnar structure with proton conductivity up to $5.5 \cdot 10^{-3} \mathrm{~S} \cdot \mathrm{cm}^{-1}$ [16]. Another example is the $\mathrm{Co}^{2+}$ carboxyphosphinate coordination polymer, however its proton conductivity is low due to the hydrophilic regions being separated by phenyl groups attached to the ligand [17]. In this case, the conduction pathway was assigned to Grotthus mechanism.

In this study, we present the synthesis and characterisation of two MOFs based on tetratopic phosphinate ligands methanetetrayltetrakis(phenyl-4-methylphosphinic acid) and tricyclo[3.3.1.1 $1^{3,7}$ decane-1,3,5,7-tetrayltetrakis(phenyl-4-methylphosphinic acid) ( $\mathrm{H}_{4}$ TPMTP(Me) and $\mathrm{H}_{4}$ TPATP(Me) respectively, see Figure 1), denoted ICR-10 and ICR-11 (ICR stands for Inorganic Chemistry Řež). Their structures have been solved using 3D electron diffraction (3D-ED) and ICR-11 represents one of the largest structures solved by 3D-ED $a b$ initio up to date. The proton conductivity of ICR-11 was investigated at various conditions, with relative humidity levels of $31 \%, 75 \%$ and $100 \%$ and temperature going up to $350 \mathrm{~K}$. 


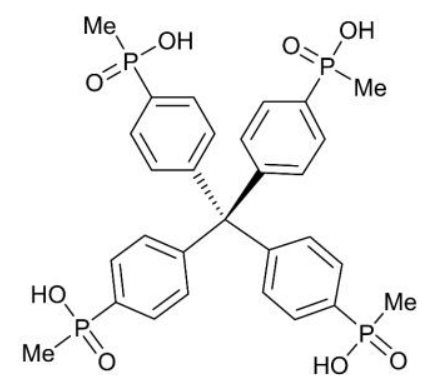

ICR-10
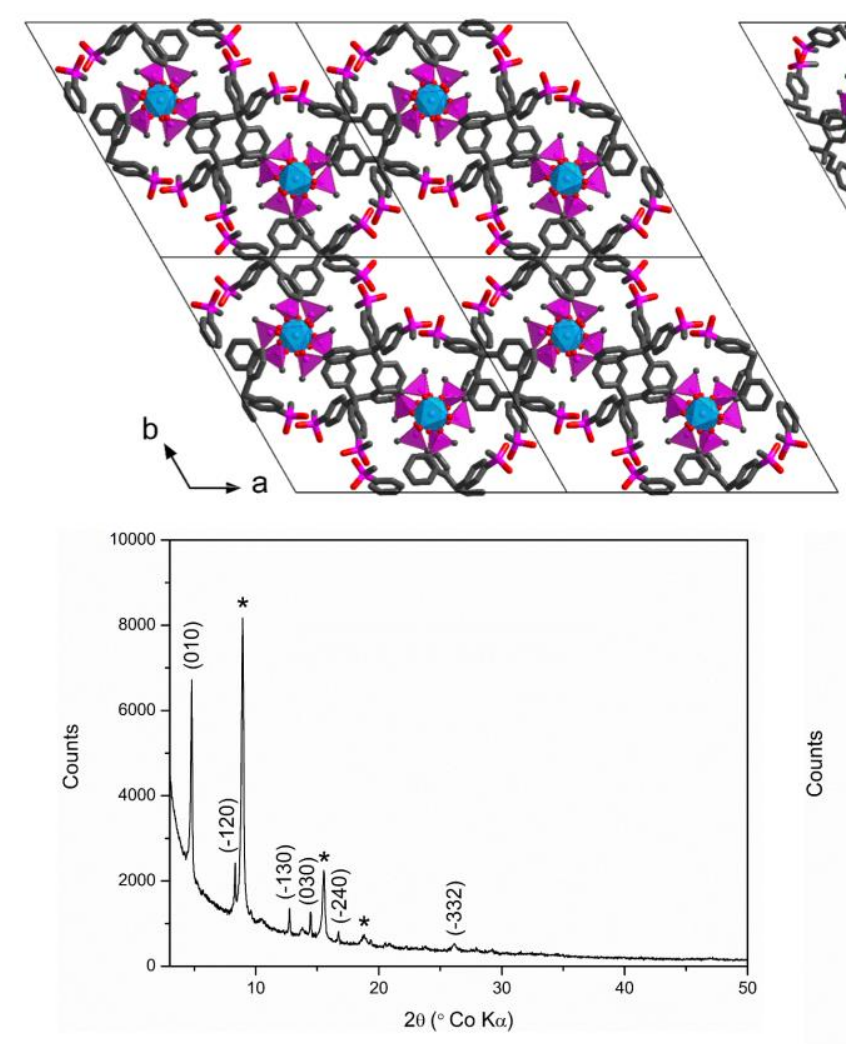

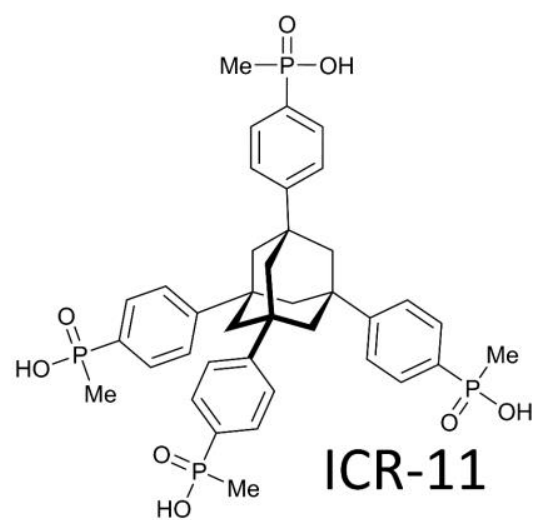

$\mathrm{HO}$

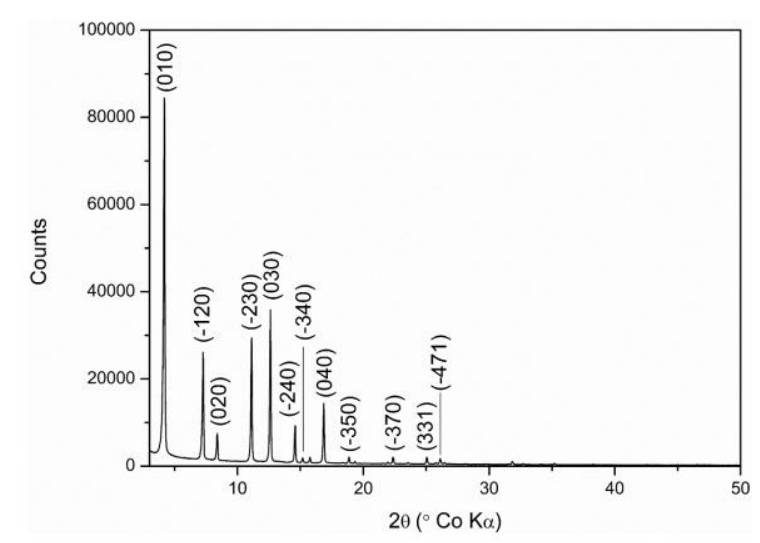

Figure 1: Phosphinate ligands used for the synthesis of ICR MOFs - $\mathrm{H}_{4}$ TPMTP(Me) (top left) and $\mathrm{H}_{4}$ TPATP(Me) (top right); honeycomb patterns of the 1D pores of ICR-10 (middle left) and ICR-11 (middle right) running along the c-axis; powder XRD patterns of ICR-10 (bottom left) and ICR-11 (bottom right). In the crystal structure of ICR-11, only one orientation of the disordered phosphinate groups is shown for clarity. In the powder XRD pattern of ICR-10, the diffraction peaks belonging to the phase impurity are marked as *.

\section{Experimental}

\section{Preparation of ICR-10}

A Teflon-lined stainless-steel autoclave (Berghof DAB-2) was charged with $11.7 \mathrm{mg}(0.020$ mmol) of $\mathrm{H}_{4}$ TPMTP(Me) and $5.4 \mathrm{mg}(0.020 \mathrm{mmol})$ of $\mathrm{FeCl}_{3} \cdot 6 \mathrm{H}_{2} \mathrm{O}$ along with $10.0 \mathrm{~mL}$ of $\mathrm{H}_{2} \mathrm{O}$ and heated to $250{ }^{\circ} \mathrm{C}$ under autogenous pressure for $24 \mathrm{~h}$. After cooling down to room temperature, the resulting white powder was centrifuged (Hettich Rottina 380R, $10000 \mathrm{rpm}, 10$ min) and washed with acetone three times. 


\section{Preparation of ICR-11}

A Teflon-lined stainless-steel autoclave (Berghof DAB-2) was charged with $17.0 \mathrm{mg}(0.024$ mmol) of $\mathrm{H}_{4} \mathrm{TPATP}(\mathrm{Me})$ and $5.4 \mathrm{mg}(0.020 \mathrm{mmol})$ of $\mathrm{FeCl}_{3} \cdot 6 \mathrm{H}_{2} \mathrm{O}$ along with $5.0 \mathrm{~mL}$ of concentrated acetic acid and heated to $250{ }^{\circ} \mathrm{C}$ under autogenous pressure for $24 \mathrm{~h}$. After cooling down to room temperature, the resulting brownish powder was centrifuged (Hettich Rottina $380 \mathrm{R}, 10000 \mathrm{rpm}, 10 \mathrm{~min}$ ) and washed with acetone three times.

\section{Structural determination}

The crystal structures of both MOFs were determined using 3D Electron diffraction (3D ED) [18]. The experiments were performed on a FEI Tecnai $\mathrm{G}^{2} 20$ microscope ( $200 \mathrm{kV}, \lambda=0.0251$ $\AA$ ) with an $\mathrm{LaB}_{6}$ cathode equipped with an Olympus SIS Veleta CCD camera (14 bit) equipped with precession unit Digistar. Samples were measured at $100 \mathrm{~K}$ (sample holder tip temperature). The powder was directly deposited on $\mathrm{Cu}$ holey-carbon TEM grid. The goniometer tilt step was $1.0^{\circ}$ and the precession angle was $0.7^{\circ}$. Data were analysed using the programs PETS 2.0 [19]. Because of the polar channel walls inside the crystal structure, and thus possible presence of water or solvent in the pores, the crystals were transferred into the microscope using a cryotransfer. No differences were observed in the quality of the diffraction data. The crystals of both MOFs are in the form of thin ribbons, which are very sensitive to the electron beam. For this reason, the crystals were scanned [20] in order to spread the dose over a larger area.

\section{Gas sorption measurement}

Adsorption isotherms were recorded using a 3P micro 300 instrument (3P Instruments) equipped with cryoTune units for measurement at different temperatures. Before the first measurement, the sample was degassed at $100{ }^{\circ} \mathrm{C}$ for $24 \mathrm{~h}$ under dynamic vacuum and then activated again at $100{ }^{\circ} \mathrm{C}$ for $1 \mathrm{~h}$ before each subsequent measurement. Adsorption of $\mathrm{N}_{2}, \mathrm{Ar}$, $\mathrm{CO}_{2}$ and $\mathrm{CH}_{4}$ was measured at their respective boiling points. Adsorption of $\mathrm{H}_{2}$ was measured at $77 \mathrm{~K}$. The BET surface area was calculated from $0.005-0.1 \mathrm{p} / \mathrm{p}_{0}$ range and the pore size distribution was calculated by HK/SF method, as provided by the 3P Instrument software.

\section{Proton conductivity measurement}

The sample for the conductivity measurements was prepared by pressing the powdered ICR-11 (15 mg) into a rectangular pellet with thickness $L$ of $1 \mathrm{~mm}$ to which $0.08 \mathrm{~cm}^{2}$ electrodes were painted using a carbon paste.

Conductivity of the samples was measured with a Metrohm Autolab PGStat12 instrumentation in a frequency range $0.05 \mathrm{~Hz}-1 \mathrm{MHz}$ with a signal amplitude of $300 \mathrm{mV}$. The impedance data in a complex impedance plot were analysed by an equivalent circuit approach using ZSimpWin software [21]. The chosen equivalent electrical circuit used for fitting consisted of a parallel arrangement of the resistance $R$ and a constant phase element (CPE), as defined by Barsoukov and MacDonald [22]. The fit provides the value of resistance $R$ from the relationship $\sigma=L / R A$, where $A$ is the area of the electrodes and $L$ is the distance between them, the conductivity $\sigma$ of the samples was calculated.

The AC conductivity was measured in the temperature range from 300 to $350 \mathrm{~K}$ for three values of relative humidity $(\mathrm{RH})$ levels $(31 \%, 75 \%$ and $100 \%)$. The relative humidity was set by equilibrating the samples in the measuring cell over a saturated solution of $\mathrm{NaCl}$ or saturated water vapor. The $31 \% \mathrm{RH}$ was the relative humidity at ambient conditions. 


\section{Results and discussion}

\section{Synthesis and characterisation}

The tetrahedrally shaped linkers based on tetrasubstituted methane $\mathrm{H}_{4} \mathrm{TPMTP}(\mathrm{Me})$ and tetrasubstituted adamantane $\mathrm{H}_{4}$ TPATP(Me) were synthetized by palladium coupling reaction of tetrabromo- derivatives with methyl methylphosphinate, for details see Supporting information. MOFs ICR-10 and ICR-11 were prepared by solvothermal crystallization of the respective linker with $\mathrm{FeCl}_{3} \cdot 6 \mathrm{H}_{2} \mathrm{O}$ in a PTFE-lined stainless-steel autoclave. ICR-10 was formed in water whereas ICR-11 in acetic acid, both at $250{ }^{\circ} \mathrm{C}$. In the case of ICR-10 the material was always obtained with an uncertain content of a phase impurity, which is demonstrated by observation of specific signals in the powder XRD pattern (Figure S2) not related to the ICR-10 structure. The SEM images (Figure S6) of the ICR-10 sample confirms the presence of two different phases, apart from the ribbon shape crystals of the desired phase there are also spherical particles of the phase impurity. On the other hand, ICR-11 reveals sufficient phase purity with only one type of particles, as documented by the powder XRD pattern (Figure S3) and SEM images (Figure S7) showing thin ribbon crystals of $1-3 \mu \mathrm{m}$ thickness and $15-50 \mu \mathrm{m}$ length. For this reason, further analyses as well as proton conductivity measurements were performed only for ICR-11. The elemental composition of ICR-11 determined by EDX spectrum (Table S1) shows values close to the theoretical atomic weight percentage. Higher content of $\mathrm{O}$ than expected is probably caused by the adsorbed water molecules.

\section{Structure determination}

\section{ICR-10}

Combination of partial datasets from 16 crystals (324 frames) gave $99.9 \%$ coverage with resolution of $0.9 \AA^{-1}$. $\mathrm{R}_{\text {int }}$ (obs/all) was $12.0 / 13.5 \%$. Structure has $P$-3 symmetry $(\mathrm{a}=24.4(1) \AA$, $\mathrm{c}=9.49(5) \AA)$ and was solved ab initio using program Superflip [23] and refined using dynamical diffraction theory [24,25] in program Jana2006/Dyngo [26].

The structure of ICR-10 (see Figure 1) contains hydrophilic channels running along the $c$-axis. The $\mathrm{FeO}_{6}$ octahedra are connected via the phosphinate groups into triply bridged 1D chains along the same axis. According to the nomenclature for phosphonates described by Tholen $e t$ al. [27], the rings formed by two $\mathrm{Fe}^{2+}$ cations and two phosphinate groups are denoted o-Fe$8 \mathrm{mpr}$ (octahedral $\mathrm{Fe} 8$-membered phosphinate rings). This chained arrangement is common in the case of phosphinate coordination polymers [28] and can be also recognized in the previously described phosphinate MOF ICR-2 [8]. Unlike ICR-2 where all phosphinate groups are coordinated to Fe, two phosphinate groups of the tetrahedral ligand in ICR-10 interconnect the iron phosphinate chains and the other two groups point towards the channels and form their hydrophilic walls.

The displacement parameters of the two ligand legs pointing inside the pores are approximately doubled compared to the rest of the ligand. This is probably caused by some level of disorder in the precise location of these ligand legs. The position of the two oxygen atoms and the methyl group on the phosphorus were clearly observed in the difference potential map, but the assignment of the atomic species was not possible because the displacement parameters were again approximately doubled in comparison with the phosphorus atom. The error bars of the bond lengths were too high to reliably distinguish between $\mathrm{P}-\mathrm{C}$ and $\mathrm{P}-\mathrm{O}$ bonds. However, for 
both vertices, it was possible to determine that the atom which was pointing towards the hydrophobic part of the structure is carbon. It is likely that some rotational disorder of the $\mathrm{P}(\mathrm{Me}) \mathrm{O}_{2} \mathrm{H}$ group occurs there. Although presence of adsorbed water molecules can be expected due to the hydrophilic nature of the channels, the difference potential map did not reveal any significant features inside the pore void. It was possible to locate 17 out of 22 hydrogen atoms [24] in the difference potential map (Figure 2). All hydrogen atoms were refined using geometrical constraints and their atomic displacement parameters were set as riding with the extension equal to 2.0. All hydrogen atoms were refined using geometrical constraints and their atomic displacement parameters were set as riding with the extension equal to 2.0.
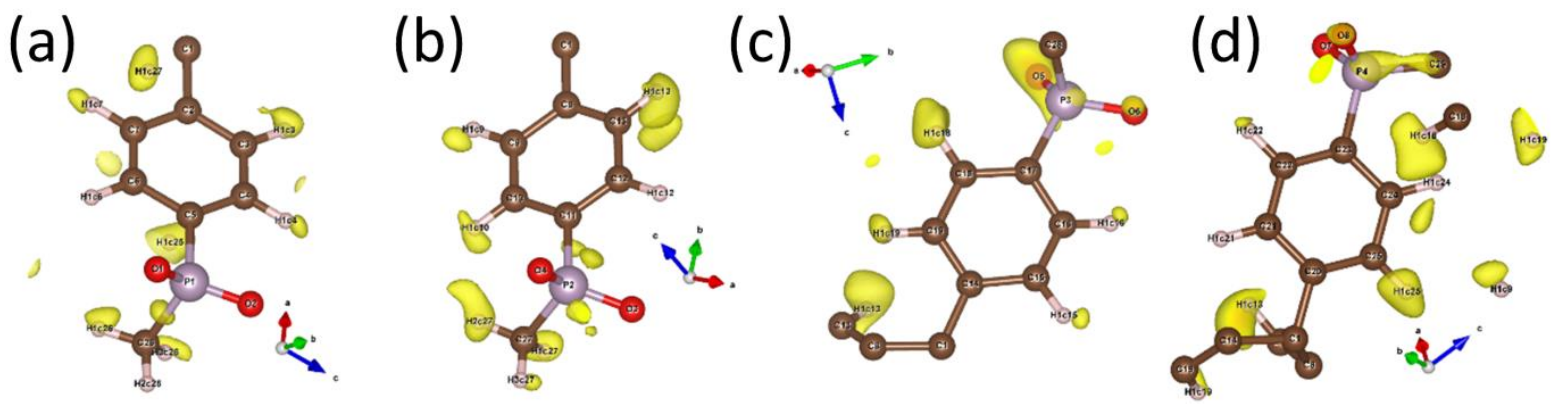

Figure 2: Difference potential map at 2.5sigma level revealing 17 out of 22 hydrogen atoms, (a) and (b) are ligand legs connecting to $\mathrm{FeO}_{6}$ octahedra, (c) and (d) are legs pointing towards the hydrophillic pores, where $-\mathrm{P}(\mathrm{Me}) \mathrm{O}_{2} \mathrm{H}$ groups are probably rotationally disordered.

\section{ICR-11}

The ICR-11 crystals are isostructural with ICR-10, crystallizing in the trigonal $P-3$ space group $(\mathrm{a}=24.3(1) \AA, \mathrm{c}=9.50(5) \AA)$. Combination of two partial datasets (90 frames) gave $99.2 \%$ coverage with resolution of $0.9 \AA^{-1}$. $\mathrm{R}_{\text {int }}$ (obs/all) was $19.8 / 31.7 \%$. The structure was solved $a b$ initio using the program Superflip. The symmetry of the structure is close to $P-3 c$, however, the systematic absences due to $c$-glide plane were clearly not present in the diffraction data. In the $h k l$ reciprocal space sections, the diffraction data showed a mirror symmetry (Figure S10), which is incompatible with the structure model. All measured diffraction data showed the same twinning, which was used during the dynamical refinement [29]. Similarly to the ICR-10 structure, the atomic displacement parameters of the two ligand legs pointing towards the pores were substantially higher than those of the rest of the structure. Since it was not possible to clearly determine the positions of the carbon and oxygen atoms of the methylphosphinic groups, the positions of these atoms were split into six symmetrical positions around the phosphorus atoms shared by $1 / 3$ of carbon and $2 / 3$ of oxygen atom with appropriate $\mathrm{P}-\mathrm{C}$ and $\mathrm{P}-\mathrm{O}$ bond lengths. The disorder can be either intrinsic to the structure or a result of the twinning.

\section{Thermogravimetric analysis}

While no significant features were observed inside the pores on the electron density map, it is expected that the hydrophilic nature of the pore walls leads to adsorption of water. This was verified by thermogravimetric analysis (Figure S8), where a broad endothermic peak occurs in the range of $60-150{ }^{\circ} \mathrm{C}$. The peak was accompanied by the loss in mass of approximately $5 \%$, which was identified as eliminated water molecules by mass spectroscopy. This mass loss corresponds to 3.25 water molecules per iron atom. 


\section{Gas sorption measurements}

The porosity of ICR-11 was probed by the adsorption of various gases. All adsorbents led to a type I isotherm (Figure 3), indicative of microporous structure. The BET surface values obtained for nitrogen $\left(228 \mathrm{~m}^{2} \mathrm{~g}^{-1}\right)$ and argon $\left(270 \mathrm{~m}^{2} \mathrm{~g}^{-1}\right)$ are in a good agreement with the theoretical value of $272 \mathrm{~m}^{2} \mathrm{~g}^{-1}$ calculated using the Poreblazer software [30]. The pore size distribution (Figure S9) was calculated from Ar adsorption isotherm using HK/SF method. The maximum indicated pore diameter was $9.7 \AA$, which is in a good agreement with the theoretical value of $9.3 \AA$. The higher sorption of $\mathrm{CO}_{2}$ compared to methane can be explained by the hydrophilic nature of the pores as can be seen from the crystal structure (Figure b).

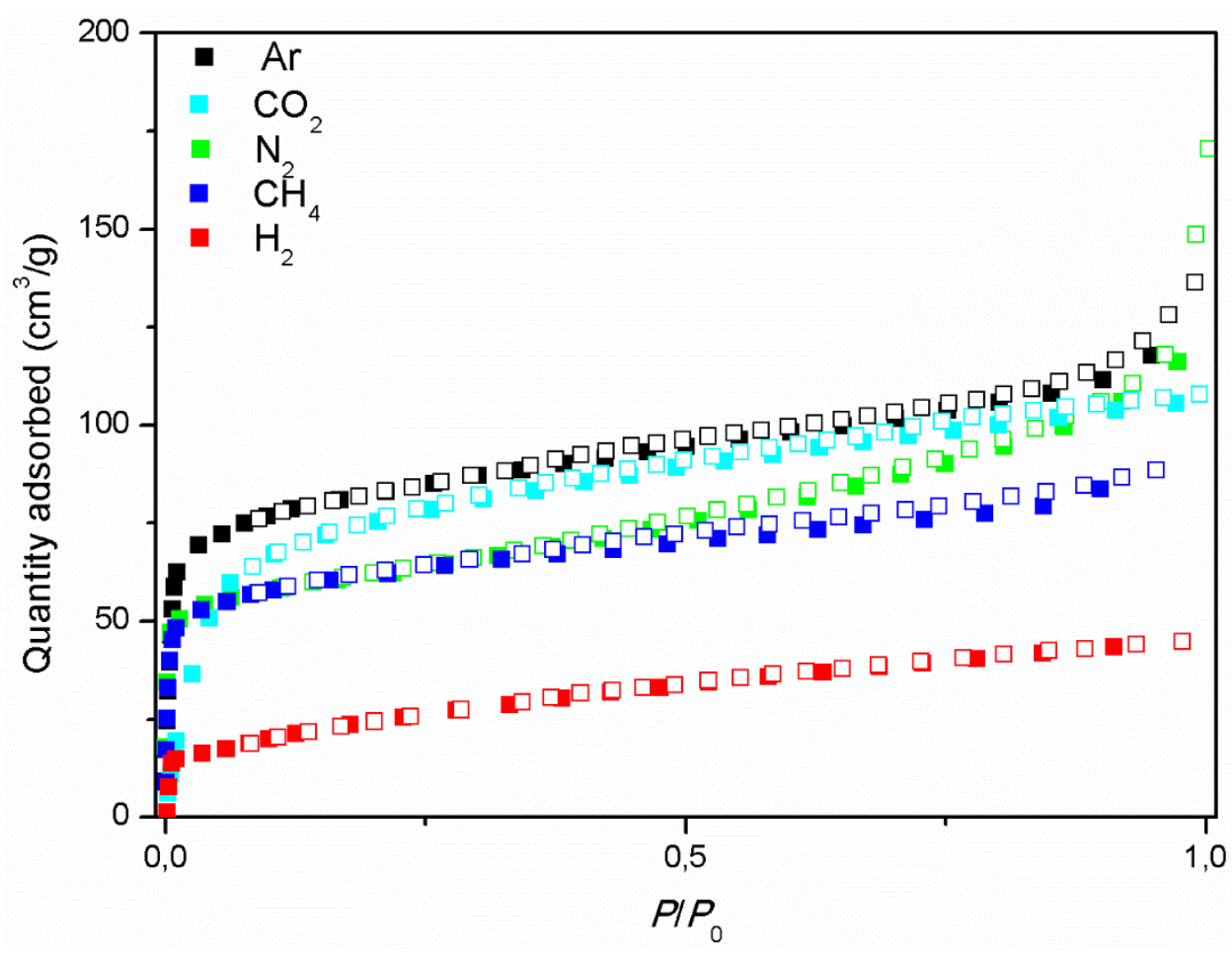

Figure 3: Adsorption isotherms for ICR-11 using $\mathrm{Ar}(87 \mathrm{~K}), \mathrm{CO}_{2}(195 \mathrm{~K}), \mathrm{N}_{2}(77 \mathrm{~K}), \mathrm{CH}_{4}$ $(112 \mathrm{~K})$ and $\mathrm{H}_{2}(77 \mathrm{~K})$ adsorbates.

\section{Proton conductivity measurements}

Since phosphonate MOFs with linear narrow pores had been described as suitable proton conductors [31], we also decided to investigate the proton conductivity of ICR-11. The AC conductivity at relative humidities of 31,75 and $100 \%$ and temperatures ranging from $300 \mathrm{~K}$ to $350 \mathrm{~K}$ are given in Table 1.

Table 1: AC conductivity of the ICR-11 sample for several temperatures measured at the relative humidity $(\mathrm{RH})$ of $31 \%, 75 \%$ and $100 \%$.

\begin{tabular}{|c|c|c|c|}
\hline \multirow[b]{2}{*}{$\mathbf{T}(\mathrm{K})$} & \multicolumn{3}{|c|}{ AC conductivity $\left(S \cdot \mathrm{cm}^{-1}\right)$} \\
\hline & RH $31 \%$ & RH $75 \%$ & RH $100 \%$ \\
\hline 300 & $1.79 \cdot 10^{-12}$ & $9.30 \cdot 10^{-8}$ & $9.22 \cdot 10^{-5}$ \\
\hline 320 & $3.84 \cdot 10^{-12}$ & $2.84 \cdot 10^{-7}$ & $1.80 \cdot 10^{-4}$ \\
\hline 340 & $7.55 \cdot 10^{-12}$ & $7.63 \cdot 10^{-7}$ & $3.25 \cdot 10^{-4}$ \\
\hline 350 & $1.03 \cdot 10^{-11}$ & $1.20 \cdot 10^{-6}$ & $4.26 \cdot 10^{-4}$ \\
\hline
\end{tabular}




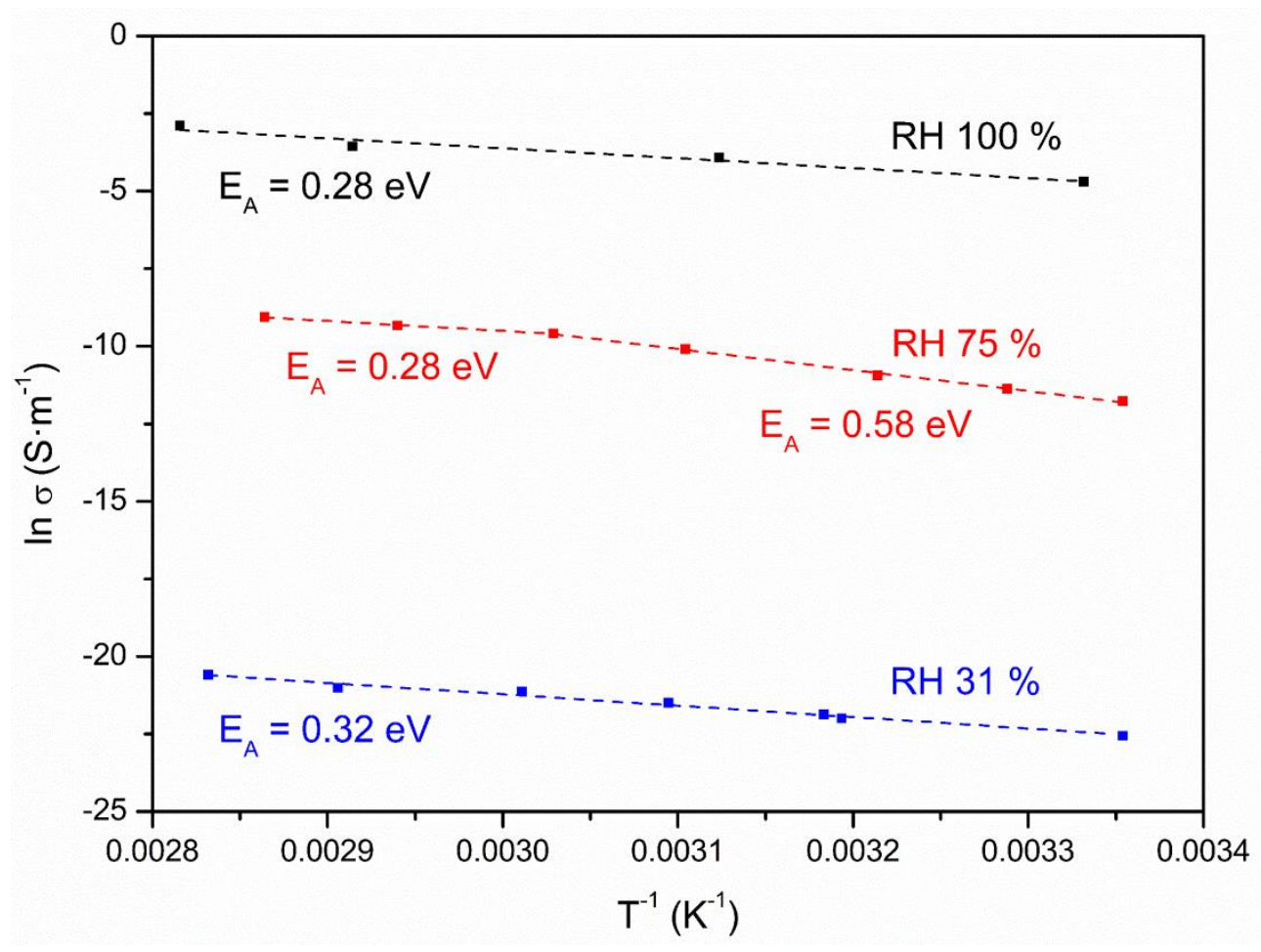

Figure 4: Arrhenius plots for ICR-11 sample at various relative humidity (RH) levels.

The conduction mechanism can be deduced from the activation energy $\left(E_{a}\right)$ shown in Figure 4 . The $E_{a}$ values determined from the dependency slopes $\ln \sigma$ vs. 1/T (Figure 4) are $0.32 \mathrm{eV}$ (30.6 $\left.\mathrm{kJ} \mathrm{mol}^{-1}\right), 0.58 \mathrm{eV}\left(55.7 \mathrm{~kJ} \mathrm{~mol}^{-1}\right)$ and $0.28 \mathrm{eV}\left(26.7 \mathrm{~kJ} \mathrm{~mol}^{-1}\right)$ for $\mathrm{RH}$ values equal to 31,75 and $100 \%$, respectively. The $E_{a}$ values in the range of $0.1-0.4 \mathrm{eV}$ suggest that the proton transport follows predominantly Grotthuss transfer mechanism [32], whereas the higher activation energy of $0.58 \mathrm{eV}$ in the lower temperature range (up to $325 \mathrm{~K}$ ) for $\mathrm{RH}=75 \%$ points out the contribution of ,vehicle" conduction pathway [33]. It is related to the conduction at grain boundaries, which is indicated by the two-semicircle shape of the Nyquist plot obtained from the impedance data in this temperature range (Figure S11b). We assume that this phenomenon results from the gradual hydration of the bulk part of the sample starting at the grain boundaries. At temperatures above $325 \mathrm{~K}$, where the process of volume hydration is completed, the activation energy $E_{a}=0.28 \mathrm{eV}$ again corresponds to the Grotthuss transport mechanism, same as in the case of $\mathrm{RH}=100 \%$. This is also indicated by the presence of a single semicircle in Nyquist's plot (Figure S12).

The linear correlation in the conductivity vs. humidity plot (Figure 5) indicates that the proton conductivity is dependent on the water content.

In comparison with another widely studied class of proton conductive materials with small linear pores, phosphonate coordination polymers, ICR-11 reveals reasonably competitive values of AC conductivity at $100 \%$ relative humidity. At ambient temperature, ICR-11 has got AC conductivity of $9.22 \cdot 10^{-5} \mathrm{~S} \mathrm{~cm}^{-1}$, which is higher than $3.5 \cdot 10^{-5} \mathrm{~S} \mathrm{~cm}^{-1}$ for PCMOF-3 reported by Shimizu et al. [34] or $2.17 \cdot 10^{-5} \mathrm{~S} \mathrm{~cm}^{-1}$ for $\left(\mathrm{Me}_{2} \mathrm{NH}_{2}\right)[\mathrm{Eu}(\mathrm{L})]$ reported by Mak et al. [35]. At elevated temperature, the AC conductivity of ICR-11 $\left(4.26 \cdot 10^{-4} \mathrm{~S} \mathrm{~cm}^{-1}\right)$ is comparable to the majority of materials from the lanthanide(III)-based PCMOF-5 family [36]. 


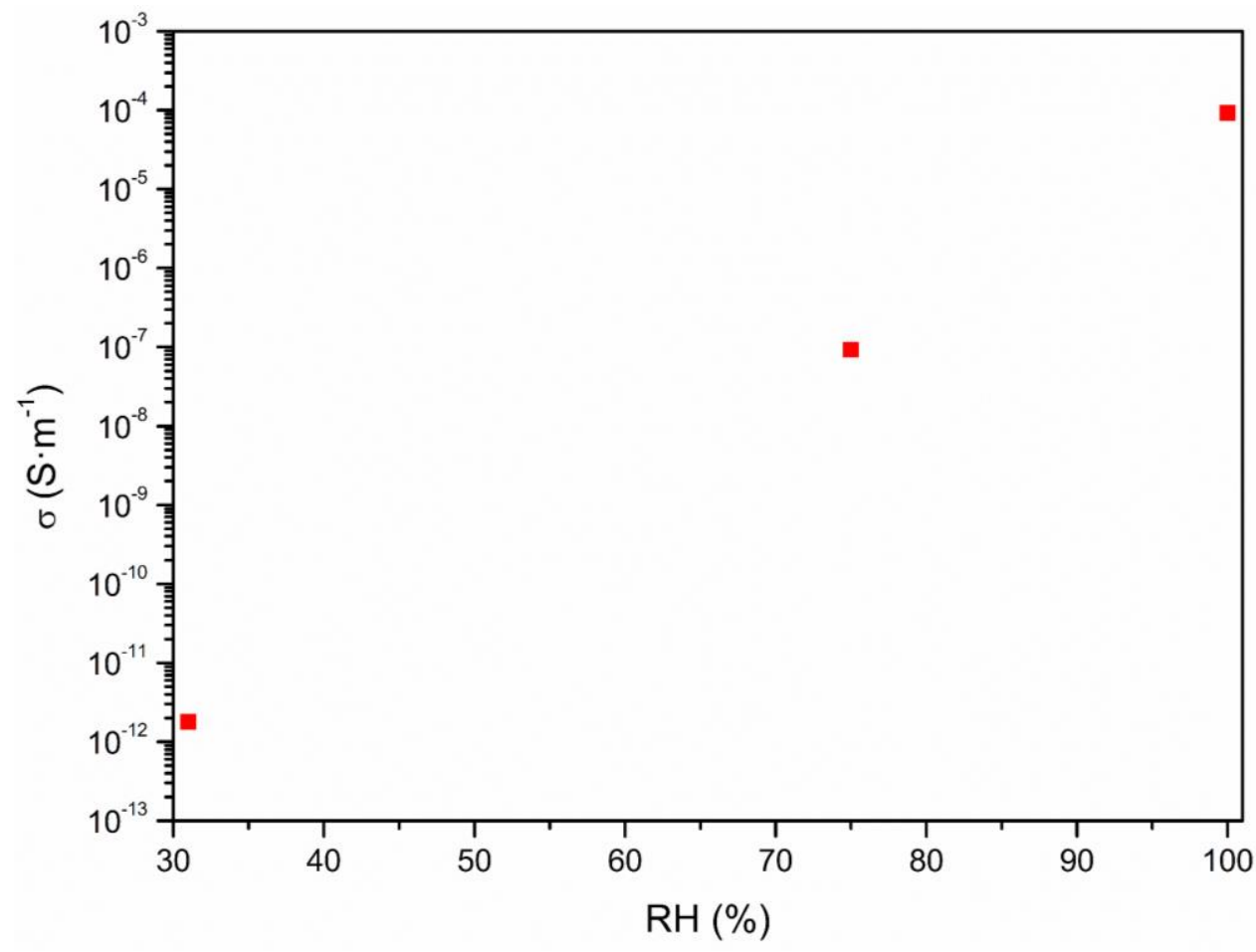

Figure 5: AC conductivity for ICR-11 at temperature $300 \mathrm{~K}$ as function of relative humidity (RH).

\section{Conclusions}

We have prepared two new MOFs based on tetratopic phosphinate ligands. The presented MOFs, ICR-10 and ICR-11, are isostructural and crystallize in the $P-3$ space group with an array of parallel hydrophilic pores along the $c$ axis. Both crystal structures were determined $a b$ initio by $3 \mathrm{D}$ electron diffraction. The unit cell volume of $6074 \AA^{3}$ and 52 non-hydrogen atoms in the independent part makes ICR-11 one of the largest MOF structures solved $a b$ initio by electron diffraction to date.

ICR-11, which was prepared in sufficient phase purity, reveals BET surface area of $270 \mathrm{~cm}^{2} \mathrm{~g}^{-1}$ and pore diameter of $9.7 \AA$ (both determined from Ar adsorption), which is in good agreement with theoretical values calculated from the structure $\left(272 \mathrm{~cm}^{2} \mathrm{~g}^{-1}\right.$ and $9.3 \AA$, respectively). Due to the presence of non-coordinated phosphinate groups, the pores in ICR-11 are hydrophilic and contain a network of hydrogen bonded water molecules, which was confirmed by thermogravimetric analysis. This enables the material to serve as a proton conductor with the conductivity of $4.26 \cdot 10^{-4} \mathrm{~S} \mathrm{~cm}^{-1}$ at $100 \%$ relative humidity and temperature of $350 \mathrm{~K}$. The activation energy values in the range of $0.1-0.4 \mathrm{eV}$ indicate the Grotthuss mechanism of conductivity and the linear dependence of conductivity on relative humidity confirms that the conductivity is facilitated by the water molecules inside the pores.

\section{References}

1 Kreuer, K.-D. Proton Conductivity: Materials and Applications. Chem. Mater. 1996, 8 (3), 610-641. https://doi.org/10.1021/cm950192a.

2 Mauritz, K. A.; Moore, R. B. State of Understanding of Nafion. Chem. Rev. 2004, 104 (10), 4535-4586. https://doi.org/10.1021/cr0207123. 
3 Ramaswamy, P.; Wong, N. E.; Shimizu, G. K. H. MOFs as Proton Conductors - Challenges and Opportunities. Chem. Soc. Rev. 2014, 43 (16), 5913-5932.

https://doi.org/10.1039/c4cs00093e.

4 Jeong, N. C.; Samanta, B.; Lee, C. Y.; Farha, O. K.; Hupp, J. T. Coordination-Chemistry Control of Proton Conductivity in the Iconic Metal-Organic Framework Material HKUST-1. J. Am. Chem. Soc. 2011, 134 (1), 51-54. https://doi.org/10.1021/ja2110152.

5 Shigematsu, A.; Yamada, T.; Kitagawa, H. Wide Control of Proton Conductivity in Porous Coordination Polymers. J. Am. Chem. Soc. 2011, 133 (7), 2034-2036.

https://doi.org/10.1021/ja109810w.

6 Ponomareva, V. G.; Kovalenko, K. A.; Chupakhin, A. P.; Dybtsev, D. N.; Shutova, E. S.; Fedin, V. P. Imparting High Proton Conductivity to a Metal-Organic Framework Material by Controlled Acid Impregnation. J. Am. Chem. Soc. 2012, 134 (38), 15640-15643.

https://doi.org/10.1021/ja305587n.

7 Costantino, F.; Donnadio, A.; Casciola, M. Survey on the Phase Transitions and Their Effect on the Ion-Exchange and on the Proton-Conduction Properties of a Flexible and Robust Zr Phosphonate Coordination Polymer. Inorg. Chem. 2012, 51 (12), 6992-7000.

https://doi.org/10.1021/ic3009656.

8 Hynek, J.; Brázda, P.; Rohlíček, J.; Londesborough, M. G. S.; Demel, J. Phosphinic Acid Based Linkers: Building Blocks in Metal-Organic Framework. Angew. Chem. Int. Ed. 2018, 57 (18), 5016-5019. https://doi.org/10.1002/anie.201800884.

9 Bůžek, D.; Ondrušová, S.; Hynek, J.; Kovář, P.; Lang, K.; Rohlíček, J.; Demel, J. Robust Aluminum and Iron Phosphinate Metal-Organic Frameworks for Efficient Removal of Bisphenol A. Inorg. Chem. 2020, 59 (8), 5538-5545.

https://doi.org/10.1021/acs.inorgchem.0c00201.

10 Bao, S.-S.; Shimizu, G. K. H.; Zheng, L.-M. Proton Conductive Metal Phosphonate Frameworks. Coord. Chem. Rev. 2019, 378, 577-594.

https://doi.org/10.1016/j.ccr.2017.11.029.

11 Colodrero, R. M. P.; Salcedo, I. R.; Bazaga-García, M.; Milla-Pérez, D. F.; Durán-Martín, J. D.; Losilla, E. R.; Moreno-Real, L.; Rius, J.; Aranda, M. A. G.; Demadis, K. D., OliveraPastor, P.; Cabeza, A. Structural variability in $\mathrm{M}^{2+}$ 2-hydroxyphosphonoacetate moderate proton conductors. Pure Appl. Chem. 2017, 89, 75-87. https://doi.org/10.1515/pac-2016-1003.

12 Bazaga-García, M.; Angeli, G. K.; Papathanasiou, K. E.; Salcedo, I. R.; Olivera-Pastor, P.; Losilla, E. R.; Choquesillo-Lazarte, D.; Hix, G. B.; Cabeza, A.; Demadis, K. D. Luminescent and Proton Conducting Lanthanide Coordination Networks Based On a Zwitterionic Tripodal Triphosphonate. Inorg. Chem. 2016, 55, 7414-7424.

https://doi.org/10.1021/acs.inorgchem.6b00570.

13 Shearan, S. J. I.; Stock, N.; Emmerling, F.; Demel, J.; Wright, P. A.; Demadis, K. D.; Vassaki, M.; Costantino, F.; Vivani, R.; Sallard, S.; Ruiz Salcedo, I.; Cabeza, A.; Taddei, M. New Directions in Metal Phosphonate and Phosphinate Chemistry. Crystals 2019, 9 (5), 270. https://doi.org/10.3390/cryst9050270.

14 Tholen, P.; Zorlu, Y.; Beckmann, J.; Yücesan, G. Probing Isoreticular Expansions in Phosphonate MOFs and Their Applications. Eur. J. Inorg. Chem. 2020, 2020 (17), 15421554. https://doi.org/10.1002/ejic.201901291. 
15 Herath, M. B.; Creager, S. E.; Kitaygorodskiy, A.; DesMarteau, D. D. Perfluoroalkyl Phosphonic and Phosphinic Acids as Proton Conductors for Anhydrous Proton-Exchange Membranes. ChemPhysChem 2010, 11 (13), 2871-2878.

https://doi.org/10.1002/cphc.201000184.

16 Nakatsuka, S.; Watanabe, Y.; Kamakura, Y.; Horike, S.; Tanaka, D.; Hatakeyama, T. Solvent-Vapor-Induced Reversible Single-Crystal-to-Single-Crystal Transformation of a Triphosphaazatriangulene-Based Metal-Organic Framework. Angew. Chem. Int. Ed. 2019, 59 (4), 1435-1439. https://doi.org/10.1002/anie.201912195.

17 Bazaga-García, M.; Vílchez-Cózar, Á.; Maranescu, B.; Olivera-Pastor, P.; Marganovici, M.; Ilia, G.; Cabeza Díaz, A.; Visa, A.; Colodrero, R. M. P. Synthesis and Electrochemical Properties of Metal(II)-Carboxyethylphenylphosphinates. Dalton Trans. 2021, 50 (19), 65396548. https://doi.org/10.1039/d1dt00104c.

18 Gemmi, M.; Mugnaioli, E.; Gorelik, T. E.; Kolb, U.; Palatinus, L.; Boullay, P.; Hovmöller, S.; Abrahams, J. P. 3D Electron Diffraction: The Nanocrystallography Revolution. ACS Cent. Sci. 2019, 5 (8), 1315-1329. https://doi.org/10.1021/acscentsci.9b00394.

19 Palatinus, L.; Brázda, P.; Jelínek, M.; Hrdá, J.; Steciuk, G.; Klementová, M. Specifics of the Data Processing of Precession Electron Diffraction Tomography Data and Their Implementation in the Program PETS2.0. Acta Crystallogr B 2019, 75 (4), 512-522. https://doi.org/10.1107/s2052520619007534.

20 Brázda, P.; Palatinus, L.; Babor, M. Electron Diffraction Determines Molecular Absolute Configuration in a Pharmaceutical Nanocrystal. Science 2019, 364 (6441), 667-669. https://doi.org/10.1126/science.aaw2560.

21 Yeum, B. ZSimpWin, EChem Software: Ann Arbor, USA, 1999-2013.

22 Impedance Spectroscopy; Barsoukov, E., Macdonald, J. R., Eds.; John Wiley \& Sons, Inc., 2018. https://doi.org/10.1002/9781119381860.

23 Palatinus, L.; Chapuis, G. SUPERFLIP- a Computer Program for the Solution of Crystal Structures by Charge Flipping in Arbitrary Dimensions. J. Appl. Cryst. 2007, 40 (4), 786-790. https://doi.org/10.1107/s0021889807029238.

24 Palatinus, L.; Petř́iček, V.; Corrêa, C. A. Structure Refinement Using Precession Electron Diffraction Tomography and Dynamical Diffraction: Theory and Implementation. Acta Crystallogr. A 2015, 71 (2), 235-244. https://doi.org/10.1107/s2053273315001266.

25 Palatinus, L.; Brázda, P.; Boullay, P.; Perez, O.; Klementová, M.; Petit, S.; Eigner, V.; Zaarour, M.; Mintova, S. Hydrogen Positions in Single Nanocrystals Revealed by Electron Diffraction. Science 2017, 355 (6321), 166-169. https://doi.org/10.1126/science.aak9652.

26 Petrríček, V.; Dušek, M.; Palatinus, L. Crystallographic Computing System JANA2006: General Features. Z. Kristallogr. Cryst. Mater. 2014, 229 (5), 345-352. https://doi.org/10.1515/zkri-2014-1737.

27 Tholen, P.; Zorlu, Y.; Beckmann, J.; Yücesan, G. Probing Isoreticular Expansions in Phosphonate MOFs and Their Applications. Eur. J. Inorg. Chem. 2020, 2020 (17), 15421554. https://doi.org/10.1002/ejic.201901291. 
28 Kloda, M.; Ondrušová, S.; Lang, K.; Demel, J. Phosphinic Acids as Building Units in Materials Chemistry. Coord. Chem. Rev. 2021, 433, 213748.

https://doi.org/10.1016/j.ccr.2020.213748

29 Steciuk, G.; David, A.; Petř́iček, V.; Palatinus, L.; Mercey, B.; Prellier, W.; Pautrat, A.; Boullay, P. Precession Electron Diffraction Tomography on Twinned Crystals: Application to $\mathrm{CaTiO}_{3}$ Thin Films. J. Appl. Cryst. 2019, 52 (3), 626-636.

https://doi.org/10.1107/s1600576719005569.

30 Sarkisov, L.; Harrison, A. Computational Structure Characterisation Tools in Application to Ordered and Disordered Porous Materials. Mol. Simul. 2011, 37 (15), 1248-1257. https://doi.org/10.1080/08927022.2011.592832.2

31 Kim, S.; Dawson, K. W.; Gelfand, B. S.; Taylor, J. M.; Shimizu, G. K. H. Enhancing Proton Conduction in a Metal-Organic Framework by Isomorphous Ligand Replacement. $J$. Am. Chem. Soc. 2013, 135 (3), 963-966. https://doi.org/10.1021/ja310675x.

32 Agmon, N. The Grotthuss Mechanism. Chem. Phys. Lett. 1995, 244 (5-6), 456-462. https://doi.org/10.1016/0009-2614(95)00905-j.

33 Kreuer, K.-D.; Rabenau, A.; Weppner, W. Vehicle Mechanism, A New Model for the Interpretation of the Conductivity of Fast Proton Conductors. Angew. Chem. Int. Ed. Engl. 1982, 21 (3), 208-209. https://doi.org/10.1002/anie.198202082.

34 Taylor, J. M.; Mah, R. K.; Moudrakovski, I. L., Ratcliffe, C. I.; Vaidhyanathan, R.; Shimizu, G. K. H. Facile Proton Conduction via Ordered Water Molecules in a Phosphonate Metal-Organic Framework. J. Am. Chem. Soc. 2010, 132, 14055-14057. https://doi.org/10.1021/ja107035w.

35 Wei, Y.-S.; Hu, X.-P.; Han, Z.; Dong, X.-Y.; Zang, S.-Q.; Mak, T. C. W. Unique Proton Dynamics in an Efficient MOF-Based Proton Conductor. J. Am. Chem. Soc. 2017, 139, 35053512. https://doi.org/10.1021/jacs.6b12847.

36 Wong, N. E.; Ramaswamy, P.; Lee, A. S.; Gelfand, B. S.; Bladek, K. J.; Taylor, J. M.; Spasyuk, D. M.; Shimizu, G. K. H. Tuning Intrinsic and Extrinsic Proton Conduction in Metal-Organic Frameworks by the Lanthanide Contraction. J. Am. Chem. Soc. 2017, 139, 14676-14683. https://doi.org/10.1021/jacs.7b07987. 